\title{
Probing the Molecular Recognition of a DNA.RNA Hybrid Duplex ${ }^{\star \star}$
}

\author{
Richard T. Wheelhouse, \\ School of Pharmacy, University of Bradford, Bradford, BD7 1DP, UK
}

Nichola C. Garbett, James Graham Brown Cancer Center, University of Louisville, Clinical and Translational Research Building, 505 S Hancock Street, Louisville, KY 40202, USA

Niklaas J. Buurma, and Physical Organic Chemistry Centre, School of Chemistry, Cardiff University, Main Building, Park Place, Cardiff, CF10 3AT, UK

\section{Jonathan B. Chaires}

James Graham Brown Cancer Center, University of Louisville, Clinical and Translational Research Building, 505 S Hancock Street, Louisville, KY 40202, USA

Richard T. Wheelhouse: r.t.wheelhouse@brad.ac.uk

DNA.RNA hybrid duplexes are the nucleic acid structures least explored as targets in drug discovery. There is a dearth of model ligands displaying convincing structure or sequence selectivity; the secondary structures of the hybrid nucleic acid hosts are variable and complex ${ }^{[1,2]}$ Ligands selective for hybrid duplexes have potential therapeutic applications as telomerase and $\mathrm{RNaseH}$ inhibitors.

Assays for investigating small molecule interactions with DNA.RNA hybrid duplexes have only recently been developed and described. ${ }^{[3]}$ Herein their application to the discovery of a small molecule that specifically recognizes poly $(\mathrm{dA}) \cdot \operatorname{poly}(\mathrm{rU})$ is reported. An unexpected binding mode was uncovered, establishing a principle that extrapolations from pure DNA or RNA binding are invalid when considering DNA.RNA hybrid duplexes.

Competition dialysis (Fig. 1) showed that the non-classical intercalator 4,6-bis-[4'-[[2"(dimethylamino)ethyl]mercapto]phenyl]pyrimidine dihydrobromide 1 bound preferentially to quadruplex and triplex DNA structures and to the hybrid duplex poly $(\mathrm{dA}) \cdot \operatorname{poly}(\mathrm{rU})$. In duplex binding, strong preferences for both backbone and base orientation were evident: association with the poly(dA).poly(rU) hybrid duplex had $\sim 20$-fold preference over the equivalent RNA, 3-fold over DNA, and 7-fold over the alternative poly(rA)·poly(dT) hybrid.

Relative binding preferences for duplex structures were confirmed in a melting of mixtures assay in which UV melting profiles were obtained for a mixture of all four $A \cdot T(U)$ duplexes in the absence and presence of low concentrations of ligand, Fig. $2 .{ }^{[3,4]}$ Significant shifting of the melting transition of the poly $(\mathrm{dA}) \cdot$ poly $(\mathrm{rU})$ hybrid was accompanied by a lesser shift in the DNA duplex melting curve at higher ligand loading.

\footnotetext{
** The authors thank: the British Association for Cancer Research for a Mid-career Fellowship (RTW); NIH grant number GM077422 (JBC); EPSRC grant number EP/D001641/1 (NJB).

Correspondence to: Richard T. Wheelhouse, r.t. wheelhouse@brad.ac.uk.

Supporting information for this article is available on the WWW under http://www.angewandte.org or from the author.
} 
<smiles>C[NH+](C)CCSc1ccc(-c2cc(-c3ccc(SCC[N+](C)(C)C)cc3)ncn2)cc1</smiles>

CD experiments (Fig. 3a, c) further elucidated the binding interaction. As ligand $\mathbf{1}$ was titrated into the hybrid solution, the intensity of nucleic acid ellipticity (244 and $275 \mathrm{~nm}$ ) decreased but the envelope of the spectrum retained its starting shape: indicative of reduced chirality in the oligonucleotide (unwinding) due to intercalation, without alteration of the global conformation. Negative induced CD bands observed for the ligand (320 and 364.5 $\mathrm{nm}$ ) were also consistent with intercalation. ${ }^{[5]}$ Intercalation was confirmed by a preliminary analytical ultracentrifugation (AUC) experiment in which the sedimentation coefficient decreased upon ligand loading in a manner consistent with unwinding and lengthening of the duplex (Fig S3). Plots of induced CD intensity vs. ligand:base pair ratio (Fig. 3a, inset) had an inflection at a ratio of 1:10. The $10 \mathrm{bp}$ per ligand binding stoichiometry was confirmed by a Job plot (Fig. 3b).

CD titration spectra using poly (dA).[poly(dT) $]_{2}$ triplex DNA, Fig. 3c, reflected those obtained for the hybrid duplex, showing unwinding of the triplex and negative induced $\mathrm{CD}$ in the ligand $(300,360.8,328 \mathrm{~nm})$. The inflection in the induced CD plots (Fig. 3c, inset) occurred at a mixing ratio of 0.15 , i.e. $\sim 7$ bt per ligand.

Isothermal titration calorimetry (ITC) probed thermodynamic details of the binding interaction. The thermogram for ligand dilution indicated disaggregation of the ligand; data analysis using an isodesmic self-aggregation model yielded $K_{\mathrm{agg}}=4.1 \pm 0.7 \times 10^{2} \mathrm{M}^{-1}$ and $\Delta H_{\text {agg }}=-7.3 \pm 0.6 \mathrm{kcal} \mathrm{mol}^{-1}$ (Fig. S4, S5). The thermogram for ligand-hybrid interaction indicated (at least) two types of binding site (Fig. 4). ITC data were analyzed using a model describing two consecutive binding events and a model describing two independent binding events; both models incorporated simultaneous ligand self aggregation (Scheme S1). Strong parameter correlation meant that the two types of site could not be quantified independently in a statistically-meaningful way. Nevertheless, analysis of parameter correlation plots concluded that the two binding events are a major binding site of $10 \mathrm{bp}$ in combination with a minor binding event involving ligand association with (potentiallyfraying) ends and gaps (supporting information). The overall binding stoichiometry is consistent with other experimental data for this system and simulated data based on binding parameters from ITC reproduced UV titrations well (Fig. S11).

In conclusion, biarylpyrimidine 1 shows a strong preference for binding the poly(dA) -poly(rU) hybrid over all other duplex nucleic acid structures and as a DNA.RNA hybrid binder, inhibited $\mathrm{RNaseH}^{[3]}$ with $\mathrm{IC}_{50}=29.5 \pm 0.2 \mu \mathrm{M}$ (Fig. 5).

All experimental data indicated that each ligand occupied a $10 \mathrm{bp}$ site; CD and AUC data unambiguously showed nucleic acid intercalation. The non-classical intercalator has flexibility of torsion angles between the three aromatic rings. This flexibility may contribute to the binding preference for the A-like hybrid by allowing the ligand to accommodate closely to propeller-twisted base pairs. ${ }^{[6]}$ Ligand $\mathbf{1}$ also showed binding preferences for triplex and quadruplex nucleic acids. Moreover, triplex poly $(\mathrm{dA}) \cdot[\text { poly }(\mathrm{dT})]_{2}$ also exists in an A-like helix. It seems, therefore, that the binding preferences discovered are selection for the global A-like structure. In contrast to major groove-binding aminoglycosides, ${ }^{[7]}$ the binding event did not drive a change in the global nucleic acid conformation. Even though the two ligand classes share correlating preferences for triplex structures ${ }^{[8]}$ there was also no evidence that ligand $\mathbf{1}$ induced hybrid duplex $\rightarrow$ triplex transitions. 
Ligand 1 did not bind to the other A-form structure in Fig. 1, the RNA duplex poly(rA) -poly(rU), an observation in contrast to the aminoglycosides, where binding to equivalent RNA duplexes was strong. ${ }^{[7]}$ An explanation may lie in the grooves and the dimensions of the ligand. The ligand possesses two cationic side chains and it may be postulated that one lies in the minor groove. Although the 2'-OH and associated solvation waters of a single RNA strand offer potential hydrogen bonding sites to the terminal ammonium functionality, these groups occlude the minor groove of the pure RNA duplex. Such steric constraints would also account for the reduced affinity of bulkier analogs of ligand $\mathbf{1}$ for the hybrid duplex (Fig. S12). Indeed the hybrid minor groove appears inaccessible to all but the smallest groups: pentamidine, berenil, Hoechst 33258 and DAPI all failed to stabilize either of the hybrid duplexes in the melting of mixtures assay. ${ }^{[3]}$

Binding rules for DNA.RNA duplexes are ill-defined and this study shows that naïve extrapolation from duplex binding models is inappropriate. The structural basis for the $\sim 10$ bp major binding site size is not yet clear but is equivalent to $\sim 1$ ligand per helical turn. The intercalator ethidium has been shown to exclude 3 or $7 \mathrm{bp}$ when bound to the poly(dA) -poly(rU) hybrid. ${ }^{[9,10]}$ and precedent for long-range transmission of binding effects over tens to hundreds of bp exists in the daunorubicin-driven $\mathrm{Z} \rightarrow \mathrm{B}$ conversion of [poly $(\mathrm{dGdC})]_{2}$. [11]

DNA.RNA hybrids and DNA triplexes both adopt structures intermediate between classic B-form DNA and A-form RNA. The correlation between binding data for ligand $\mathbf{1}$ and its analogs to these two structures is striking (Figs. 3 and S13) and demonstrates that the search for structure and sequence selective ligands for DNA.RNA hybrid duplexes should start with re-evaluation of DNA triplex-targeting compounds.

\section{Experimental Section}

Compound 1 was synthesized as previously described. ${ }^{[12,13]}$ Oligonucleotides for CD and calorimetry were obtained from Midland Certified Reagent Co, Midland, TX (poly(dA), lot 111997, 126-1200 nucleotides; poly(rU) lot 102197, 500-2600 nucleotides). All other oligonucleotides were purchased from Sigma, Milwaukee, WI, USA or Poole, UK.

CD spectra were recorded on a Jasco J-810 spectropolarimeter with Peltier. UV melting experiments were performed on a Cary 400Bio spectrophotometer equipped with Peltier. Other spectra were recorded on a Jasco V-550 spectrophotometer and Tecan Safire 2 microplate reader. ITC was performed on a Microcal VP-ITC calorimeter.

Competition dialysis, ${ }^{[3,14-17]}$ melting of mixtures ${ }^{[3,4]}$ and RNaseH assays ${ }^{[3,4]}$ followed published protocols.

Job plots: the protocol followed that set out by Jenkins ${ }^{[18]}$ but detected by UV. Mixtures of $\mathbf{1}$ and poly(dA)-poly(rU) to a summed concentration of $100 \mu \mathrm{M}$ in BPES pH 6.00 were set up in duplicate on a 96 well microtitre plate. Reference solutions had buffer in place of nucleic acid. Spectra were recorded from $230-450 \mathrm{~nm}$. Absorbance data for the drug maximum at $356 \mathrm{~nm}$ were extracted and the free drug absorbance subtracted from that of the drug-nucleic acid complex before plotting $\mathrm{A}_{356} \mathrm{vs}$. mole fraction of ligand.

CD Titrations: nucleic acid solutions in BPES pH $6.00(1 \mathrm{ml})$ were prepared to have $\mathrm{A}_{257}$ $\sim 0.8$ and placed in a $1 \mathrm{~cm}$ pathlength quartz cuvette equipped with stirrer. Concentrated ligand solutions were prepared in the same buffer to minimize volume changes during titration. Aliquots were added until precipitation of the ligand-nucleic acid complex was evident. Raw data were corrected for dilution before plotting and analysis. 
ITC: all experiments were performed in BPES pH 6.00. Oligonucleotides were dissolved in buffer, dialyzed against buffer ( 3 changes of solution) and the final dialysate used as solvent for all reactions and dilution of reagents. In a typical experiment, a solution of poly(dA) -poly(rU) $(0.5 \mathrm{mM}(\mathrm{bp}))$ was loaded into the calorimeter cell and ligand $1(0.25 \mathrm{mM})$ loaded into the syringe; aliquots $(10 \mu \mathrm{l})$ were added at intervals of $360 \mathrm{~s}$. To determine the heats of dilution, a solution of $\mathbf{1}(5 \mathrm{mM})$ was titrated ( $15 \mu \mathrm{l}$ aliquots, $360 \mathrm{~s})$ into buffer. Other control titrations of buffer into nucleic acid and buffer into buffer were also performed. Data were treated in Origin (Microcal, Inc) to generate integrated heat effects per injection $(\Delta \mathrm{h})$. These were analyzed using IC ITC following published procedures. ${ }^{[19,20]}$ Ligand self-aggregation parameters were determined from ligand dilution experiments and held constant in subsequent analyses of binding data.

\section{References}

1. Shaw NN, Arya DP. Biochimie. 2008; 90:1026. [PubMed: 18486626]

2. Gyi JI, Conn GL, Lane AN, Brown T. Biochemistry. 1996; 35:12538. [PubMed: 8823191]

3. Wheelhouse, RT.; Chaires, JB. Drug-DNA Interaction Protocols. 2nd ed.. Fox, KR., editor. Springer; 2010.

4. Shi XC, Chaires JB. Nucleic Acids Res. 2006; 34:e14. [PubMed: 16432258]

5. Garbett NC, Ragazzon PA, Chaires JB. Nat. Protoc. 2007; 2:3166. [PubMed: 18079716]

6. Wilson WD, Tanious FA, Watson RA, Barton HJ, Strekowska A, Boykin DW, Strekowski L. Biochemistry. 1989; 28:1984. [PubMed: 2719941]

7. Barbieri CM, Li TK, Guo S, Wang G, Shallop AJ, Pan W, Yang G, Gaffney BL, Jones RA, Pilch DS. J. Am. Chem. Soc. 2003; 125:6469. [PubMed: 12785787]

8. Arya DP, Coffee RL Jr, Charles I. J. Am. Chem. Soc. 2001; 123:11093. [PubMed: 11686727]

9. Lehrman EA, Crothers DM. Nucleic Acids Res. 1977; 4:1381. [PubMed: 896465]

10. Shaw NN, Xi H, Arya DP. Bioorg. Med. Chem. Lett. 2008; 18:4142. [PubMed: 18573660]

11. Qu X, Trent JO, Fokt I, Priebe W, Chaires JB. Proc. Natl. Acad. Sci. USA. 2000; 97:12032. [PubMed: 11027298]

12. Wheelhouse RT, Jennings SA, Phillips VA, Pletsas D, Murphy PM, Garbett NC, Chaires JB, Jenkins TC. J. Med. Chem. 2006; 49:5187. [PubMed: 16913707]

13. Murphy PM, Phillips VA, Jennings SA, Garbett NC, Chaires JB, Jenkins TC, Wheelhouse RT. Chem. Commun. 2003:1160.

14. Ren JS, Chaires JB. Biochemistry. 1999; 38:16067. [PubMed: 10587429]

15. Ren JS, Chaires JB. J. Am. Chem. Soc. 2000; 122:424.

16. Ren JS, Chaires JB. Methods Enzymol. 2001; 340:99. [PubMed: 11494877]

17. Chaires JB. Curr. Med. Chem. Anticancer Agents. 2005; 5:339. [PubMed: 16101486]

18. Jenkins, TC. Drug-DNA Interaction Protocols. Fox, KR., editor. Totowa, N.J., U.S.A.: Humana Press Inc.; 1997. p. 195

19. Buurma NJ, Haq I. J. Mol. Biol. 2008; 381:607. [PubMed: 18617189]

20. Buurma NJ, Haq I. Methods. 2007; 42:162. [PubMed: 17472898] 


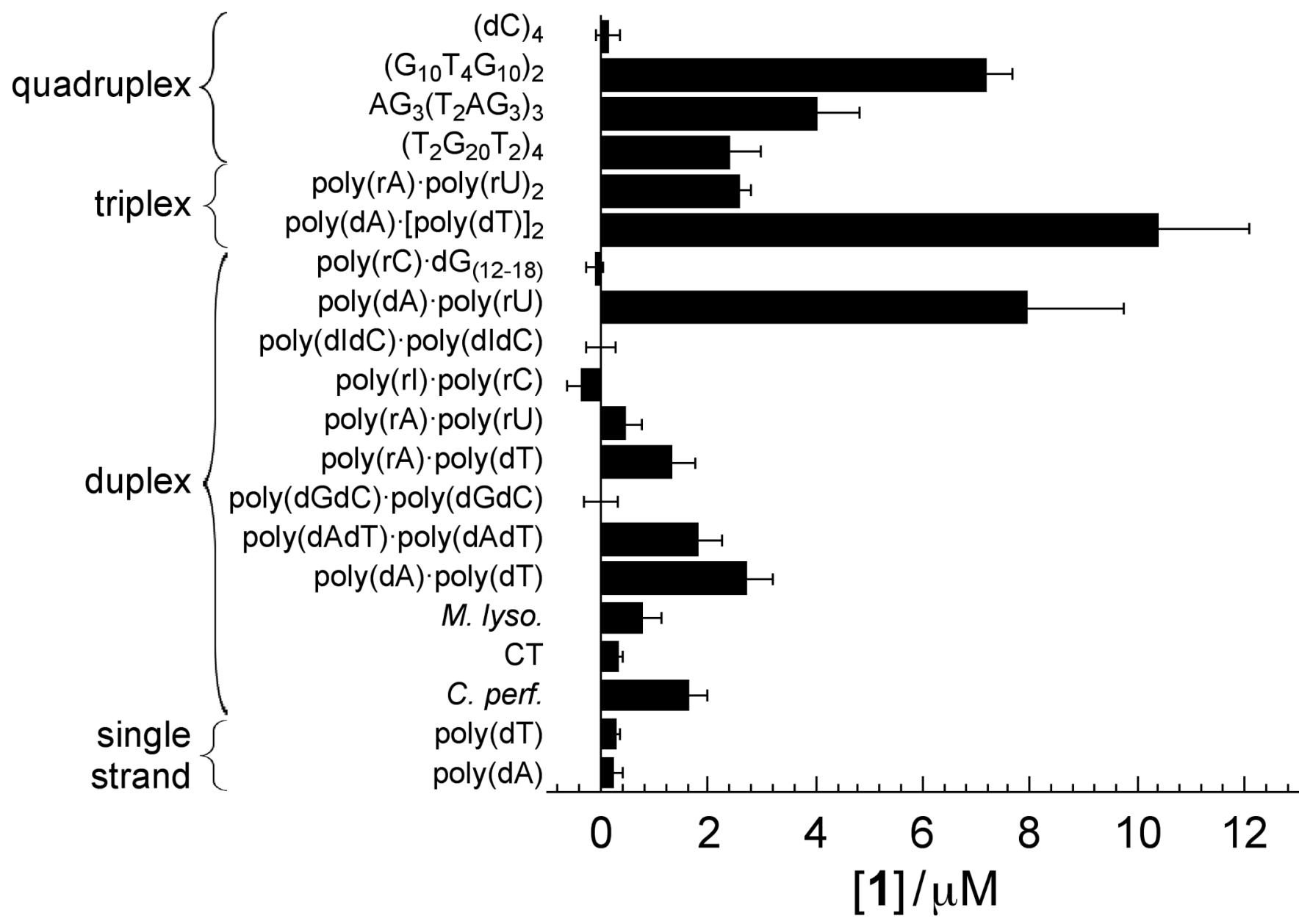

Figure 1.

Competition dialysis data for compound $\mathbf{1}$, all data are the mean \pm SD of 3 separate determinations. 


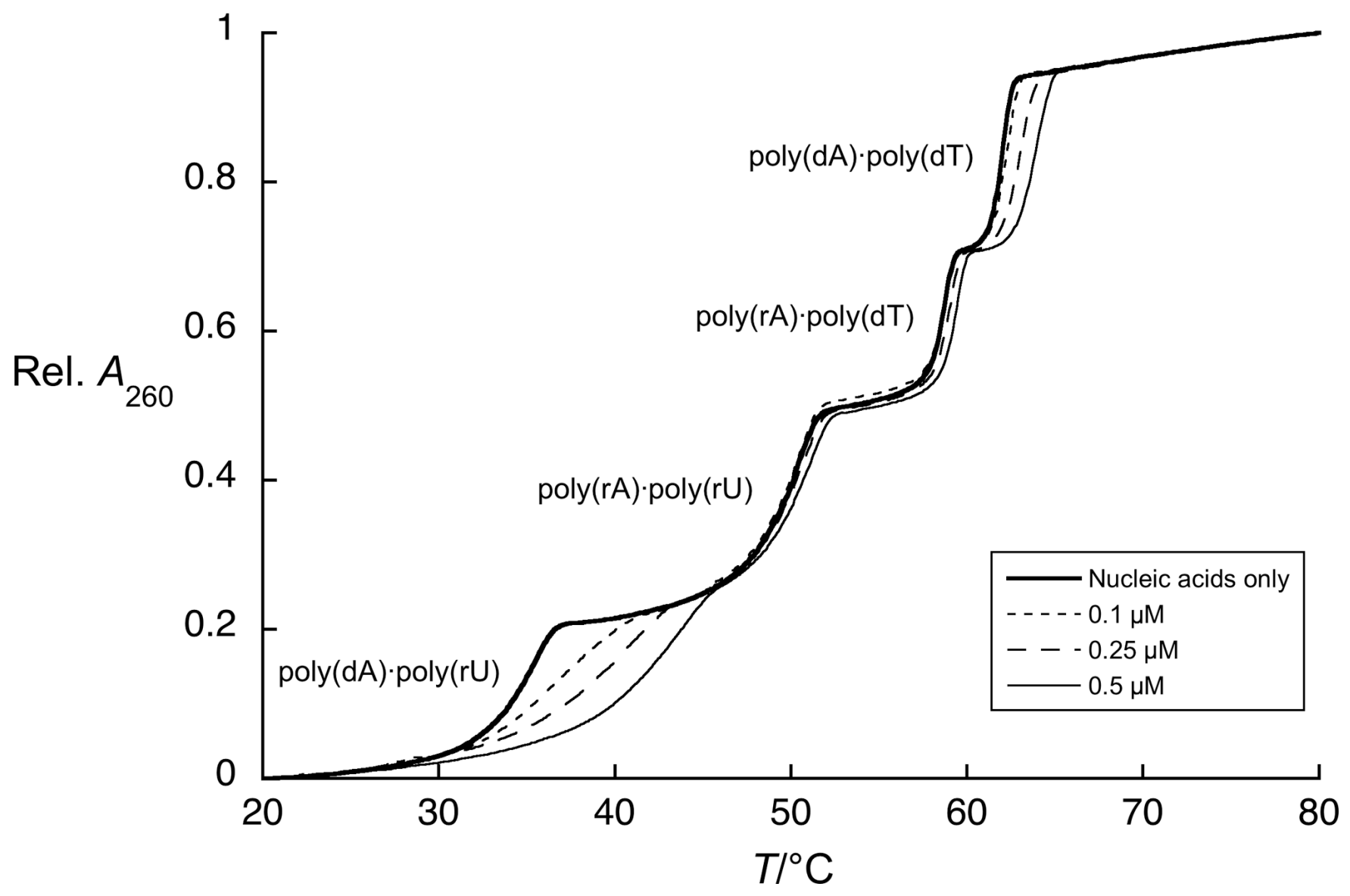

Figure 2.

Melting of mixtures data for the four A.T(U) duplexes (each $10 \mu \mathrm{M}(\mathrm{bp})$ ) in the presence of increasing concentrations of ligand $\mathbf{1}$. 

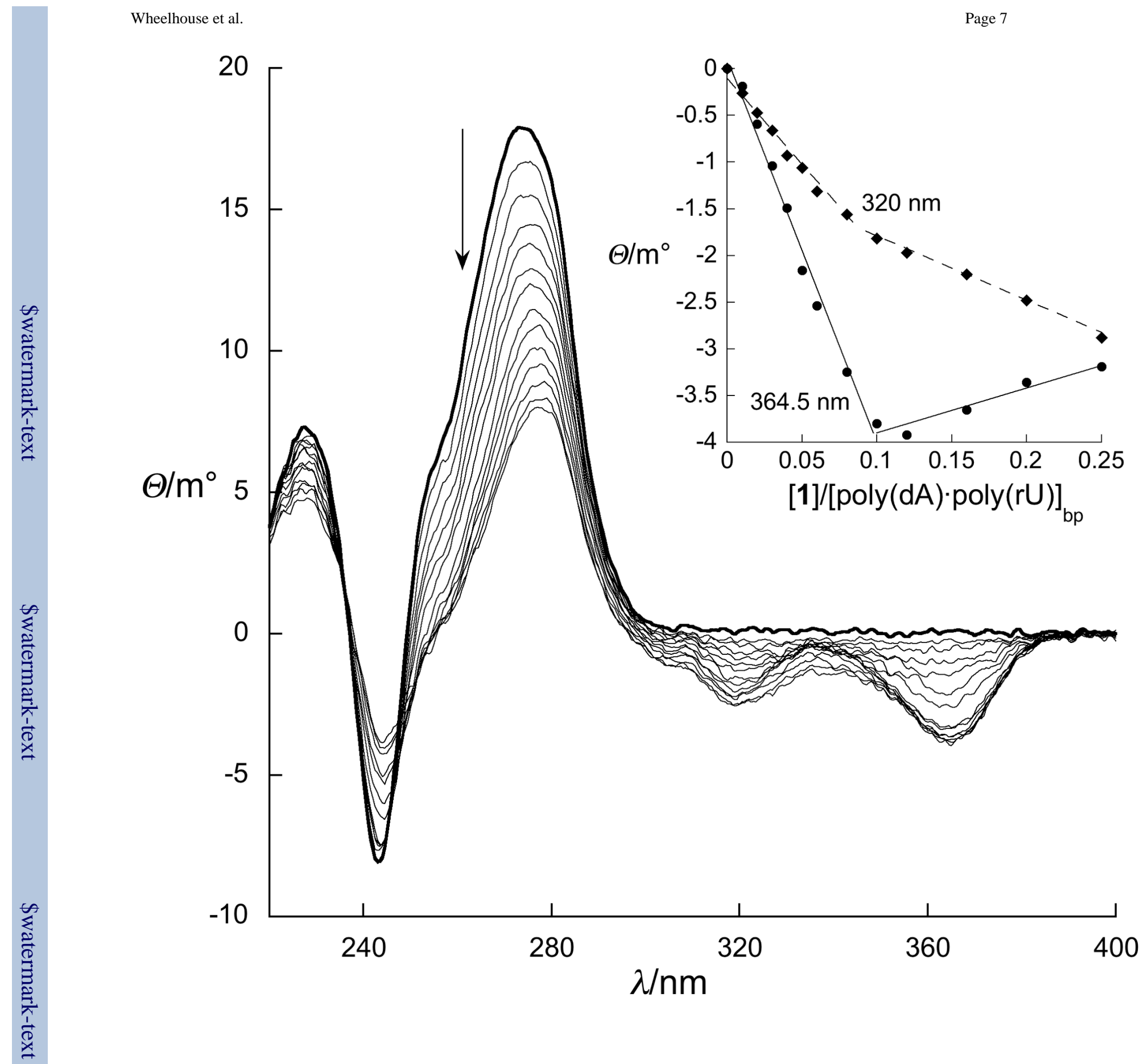


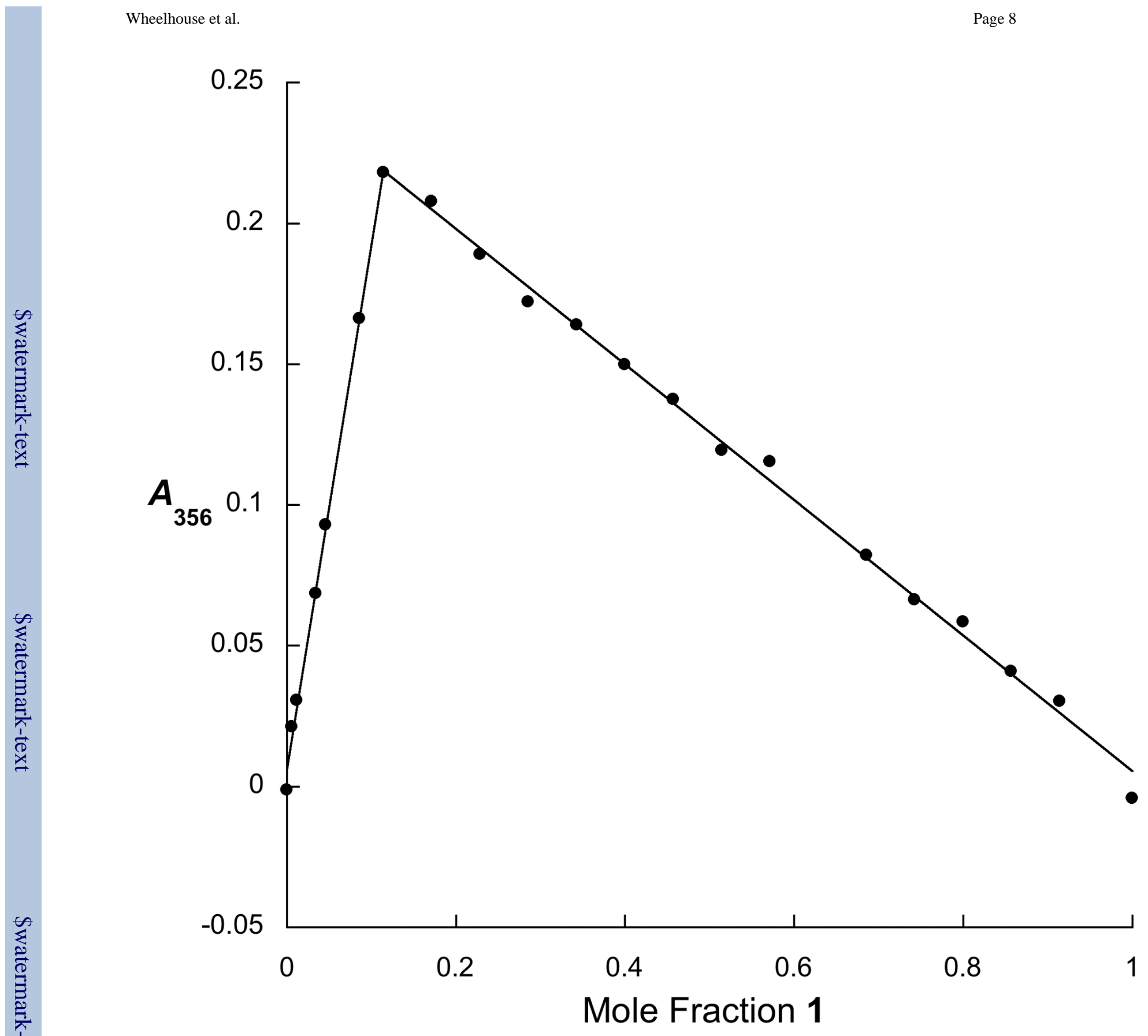




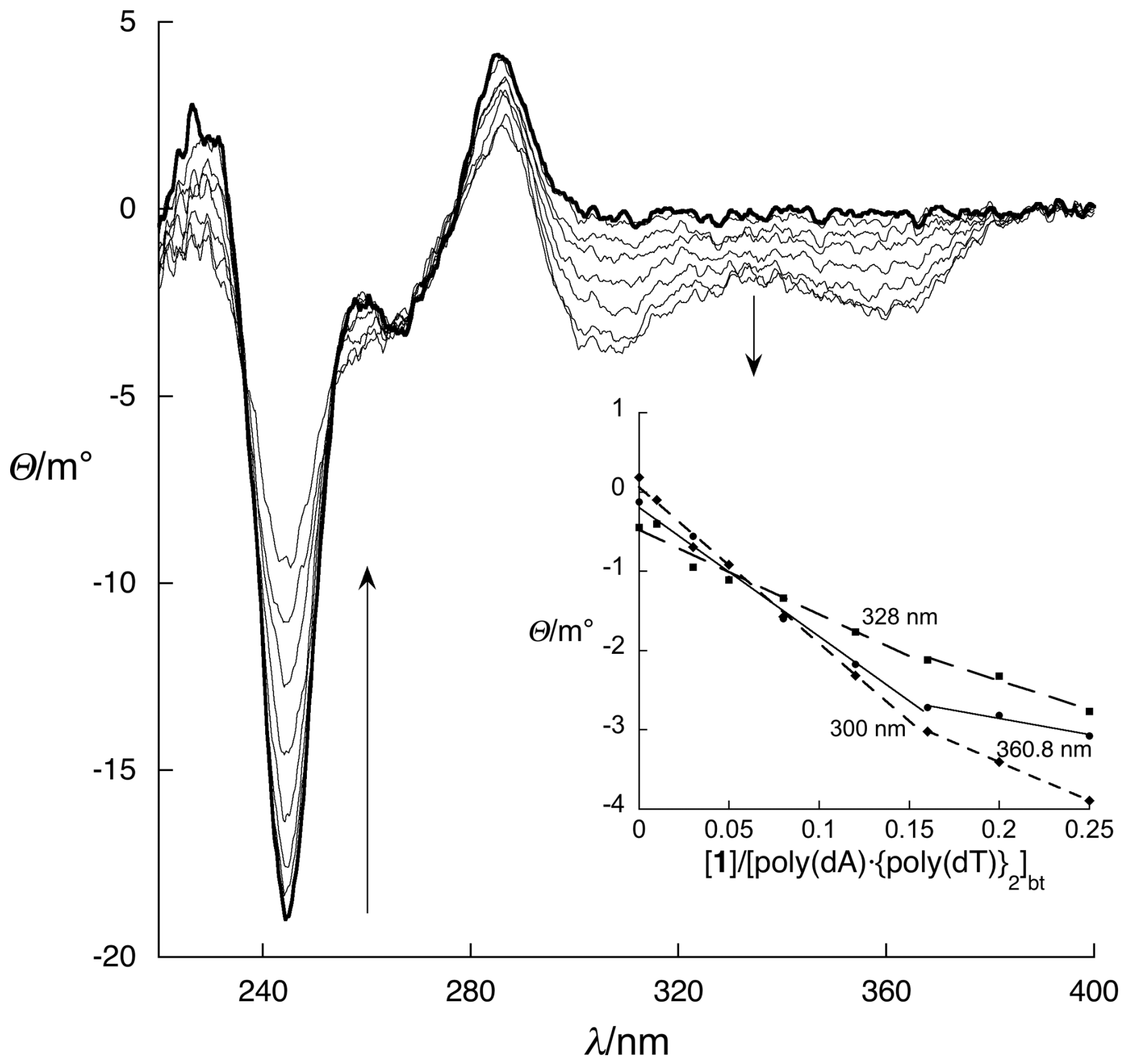

Figure 3.

a) $\mathrm{CD}$ titration of ligand $\mathbf{1}$ into poly $(\mathrm{dA}) \cdot \operatorname{poly}(\mathrm{rU})$ duplex; inset, induced $\mathrm{CD}$ as a function of the $[1] /[\operatorname{poly}(\mathrm{dA}) \cdot \operatorname{poly}(\mathrm{rU})]_{\mathrm{bp}}$ ratio. b) Job plot for mixtures of compound 1 with poly $(\mathrm{dA})$ -poly(rU) at a constant $100 \mu \mathrm{M}$. c) CD titration of ligand 1 into poly(dA). [poly(dT) $]_{2}$ triplex, the spectrum of the free nucleic acid is shown as a heavy line; inset, induced $\mathrm{CD}$ as a function of the $[1] /\left[\operatorname{poly}(\mathrm{dA}) \cdot\{\operatorname{poly}(\mathrm{dT})\}_{2}\right]_{\mathrm{bt}}$ ratio. 


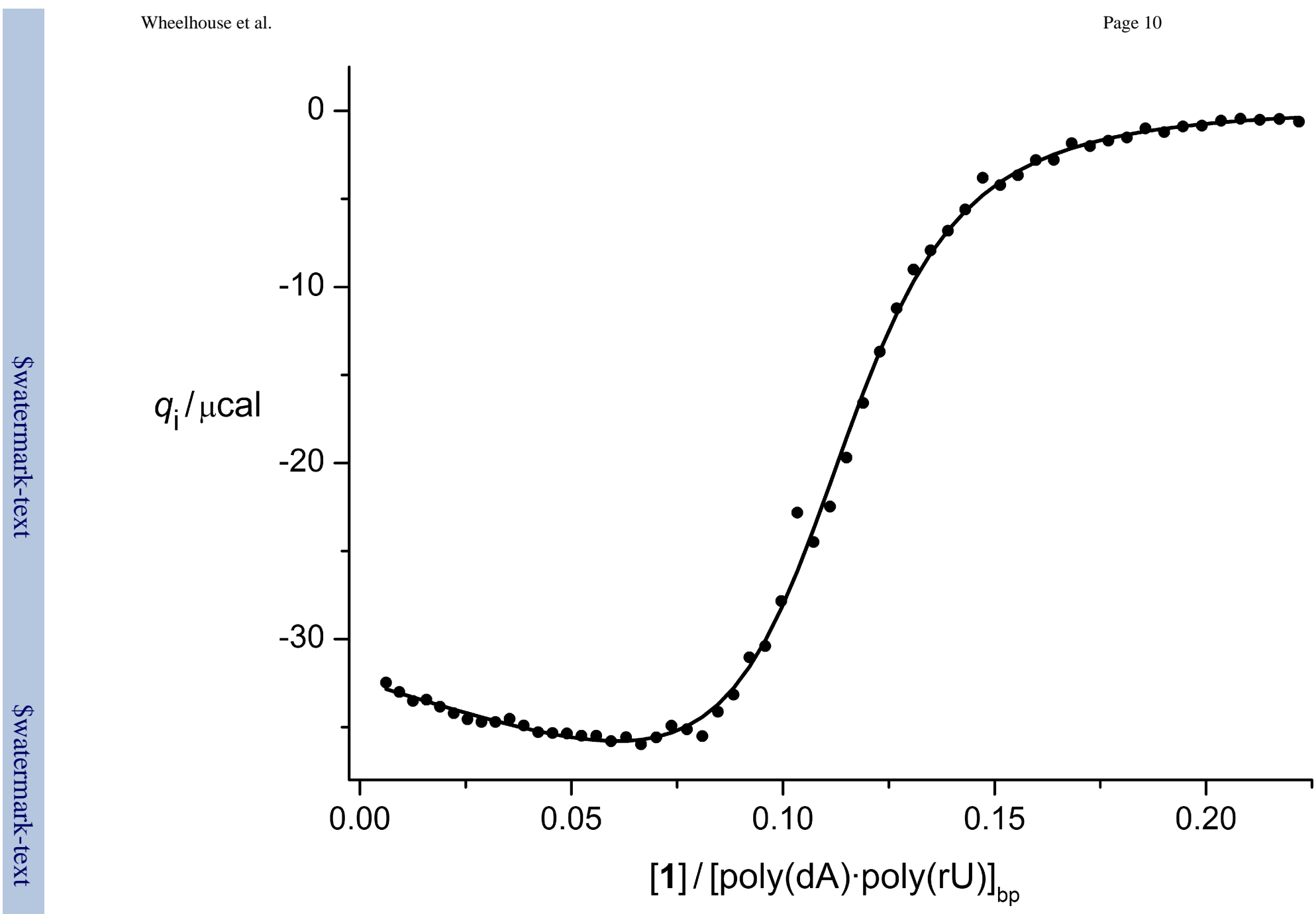

Figure 4.

Integrated heat effects for titration of ligand 1 into poly(dA)·poly(rU) fitted using a model involving a major binding site in combination with a minor binding event (see supporting information). 

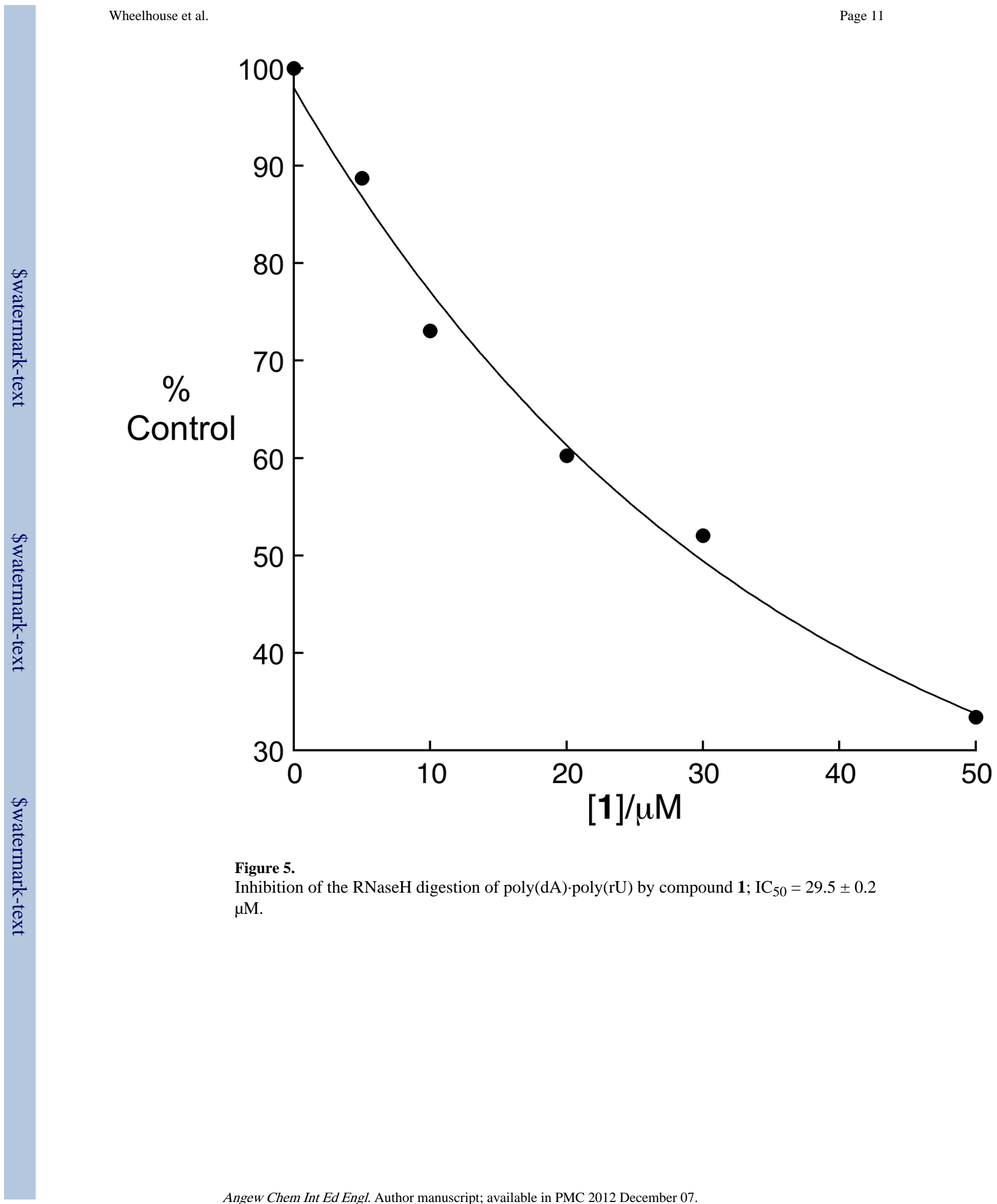

Figure 5.

Inhibition of the $\mathrm{RNaseH}$ digestion of poly $(\mathrm{dA}) \cdot \operatorname{poly}(\mathrm{rU})$ by compound $\mathbf{1}$; $\mathrm{IC}_{50}=29.5 \pm 0.2$ $\mu \mathrm{M}$. 